\title{
Ермашенок E.B.
}

\section{Проблемы и перспективы использования электронного обучения в образовательном процессе}

\author{
Ermashenok E.V. \\ Problems and prospects of use of electronic \\ training in educational process
}

\begin{abstract}
В статье рассматриваются основные проблемы электронного образования в образовательном процессе. Выявлены главные перспективы развития электронного образования. Изучен Федеральный закон от 29.12.2012 N 273-ФЗ «Об образовании в Российской Федерации».

Рассмотрена роль электронного обучения в образовании

Ключевые слова: электронное обучение, образование, процесс обучения
\end{abstract}

\section{Ермашенок Екатерина Владимировна} Студент

Национальный исследовательский Томский политехнический университет

2. Томск, проспект Ленина, 30

\begin{abstract}
In article the main problems of electronic education in educational process are considered. The main prospects of development of electronic education are revealed. The Federal law of 29.12.2012 N 273-FZ "About education in the Russian Federation" is studied. The role of electronic training in education is considered
\end{abstract}

Key words: electronic training, education, training process

\section{Ermashenok Ekaterina Vladimirovna Student \\ National research Tomsk polytechnic university \\ Tomsk, Lenina ave., 30}

В последние годы активно развиваются дистанционные технологии в виде онлайн обучения. На сегодняшний день применение технологий электронного обучения выходит на первый план во всем мире. В высших учебных заведениях (вузах) это выражается наиболее ярко, так как там начинают вводиться новые методы преподавания, в том числе и с помощью технологий электронного обучения, взамен традиционных педагогических практик. Таким образом, электронное обучение все глубже и глубже интегрируется в образовательный процесс в вузах, и становится неотъемлемой составляющей всех форм обучения. За счет информационных технологий постоянно и быстро пополняются мировая образовательная база знаний, студенты получают больше возможностей для получения этих знаний и самостоятельной работы по их освоению, что позволяет повысить качество образования.

Традиционно в высших учебных заведениях существовали различные формы обучения: очная (дневная), очно-заочная (вечерняя), заочная. В Законе 
«Об образовании в РФ» от 29.12.2012 N 273-Ф3, разрешено использовать сетевые формы реализации образовательной программы, использование дистанционных образовательных технологий, электронного обучения [1]. В нем определяются следующие формы получения образования: очная, очно-заочная и заочная в зависимости от объема обязательных занятий педагогических работников с обучающимися. В то же время разрешено использование образовательной организацией сетевых форм реализации образовательной программы, а также возможность использования дистанционных образовательных технологий, электронного обучения.

Введенные новые государственные обучающие стандарты создают условия для широкого использования электронного обучения, что позволяет сократить объемы аудиторных часов в вузах, создание новых форм и возможностей для самостоятельных работ студентов. По мнению О.Э. Петруня, информационно-коммуникационные технологии, используемые в электронном обучении, применяются для повышения эффективности очного обучения, предоставляют преподавателям новые педагогические приемы по работе со студентами, для повышения их мотивации к изучению нового материала. Такими информационными технологиями также называют сервисы Web 2.0, которые используются в LMS - Learning Management Systems, системах управления обучением. Эти сервисы создают среду для взаимодействия студентов с преподавателями и между собой с помощью различных социальных инструментов: блогов, вики, подкастов, социальных сетей, но использование данной технологии это только частный случай [7; 117].

Основными проблемами электронного обучения в настоящее время являются:

1. Частичное отсутствие у населения обладания достаточной компьютерной грамотностью;

2. Отсутствие «языка» визуальной выразительности (специальных технических средств для групповых онлайн лекций и консультаций);

3. Отсутствие у общества образа и понимания электронного образования как одного из видов обучения в ВУЗе;

4. Низкое качество электронного обучения, не соответствие образовательным программам;

5. Слабая конкуренция e-learning с традиционными программами образования;

6. Рассмотрение обществом электронного обучения как способа простоты получения документа об образовании;

7. Недостаточность финансирования образовательных учреждений для введения информационно-коммуникационных технологий.

Некоторые авторы убеждены в несостоятельности существующих технологий применительно к обеспечению качества подготовки кадров по заочной форме в системе высшего профессионального образования. Сегодня электронное обучение и дистанционное образование ассоциируются с простой «технологией» получения документа об образовании [4; 4]. 
Учитывая особенности организации учебного процесса при онлайн обучении в отличие от классической заочной формы, студенты должны не только обладать необходимым уровнем подготовки для получения высшего образования, которая регламентируется правилами приема в вузы, но и обладать достаточной компьютерной грамотностью, иметь навыки работы с телекоммуникационными и информационными технологиями, а также иметь необходимые технические средства.

Эти требования препятствуют выбору онлайн обучения, хотя, обычно, системы дистанционного обучения интуитивно понятны, имеют мобильные версии для работы с телефона или планшета.

В этой связи необходимо опираться на профессиональные задачи обучающихся, стараться вкраплять решение подобных задач в учебный материал, усиливать практическую направленность обучения и развивать самостоятельность обучающихся. Так как наличие опыта является отличительной чертой обучения студентов.

Кроме того онлайн обучению свойственна индивидуализация процесса, когда обучающийся общается непосредственно с преподавателем с помощью информационно-коммуникационных технологий (электронная почта, форумы в системе дистанционного обучения, видеоконференции и др.). Причем это общение во многих случаях не регламентировано временем и местом.

На взгляд некоторых авторов, таких как О.М. Карпенко, А.В. Абрамова, М.Е. Широкова, В.А. Басова, качество подготовки в системе высшего профессионального образования лежит не в технологической сфере, а в сфере адекватной аттестации студентов. Если студент, обучающийся с использованием электронного обучение и дистанционных образовательных технологий, будет четко знать критерии прохождения аттестации, то даже при слабом учебно-методическом и технологическом обеспечении учебного процесса он будет мотивирован на приобретение знаний, выработку необходимых навыков и умений.

С.А. Лебедев и В.А. Лебедев В.А. утверждают, что важно изменить психологию профессорско-преподавательского состава высших учебных заведений, в части использования единого стандарта аттестации студентов (в настоящее время профессорско-преподавательский состав использует два, а порой и три стандарта), вне зависимости от формы или технологий обучения [5; 75].

По мнению О.В. Калмыкова и А.А. Черепанова, методический потенциал новой, виртуальной культуры пока только потенциально высок. Интернет-технологии в образовательных процессах - это инструмент, который позволяет упростить решение конкретных задач [3; 17].

С.Ф. Сергеев утверждает, что в системе электронного обучения необходимо создание программ, в основе которых будут заложены современные информационные и педагогические технологии [8; 109].

По мнению автора Е.М. Бурнаева, современное электронное обучение претендует на создание такого «языка» визуальной выразительности, который бы совместил образность «большого» кино и специфику образов «малого» экрана монитора. Успехом электронных учебников и образовательных программ явля- 
ется достижение высокопрофессионального синтеза элементов высокой художественной выразительности и качественно исполненных технологических сочленений когнитивной компьютерной графики. Есть основания полагать, что именно над решением этих проблем предстоит трудиться педагогам и программистам в ближайшем будущем [2; 1243].

Таким образом, проблемы качества высшего профессионального образования с использованием электронного обучения и дистанционного образования частично решаются в рамках новых нормативно-правовых актов РФ, однако, как показывает практика, трактовка этих документов различается, в результате чего качество образования не повышается.

Для оптимизации процессов электронного обучения необходимо проведение следующих мероприятий:

1. Создание у общества реальных представлений о возможности получения качественного образования в виде электронного обучения;

2. Совершенствование и внедрение специальных усовершенствованных технических средств для групповых онлайн лекций и консультаций;

3. Обеспечить соответствие качества электронного обучения образовательным стандартам;

4. Проводить целенаправленный мониторинг адекватности аттестации студентов, что будет способствовать адекватной оценке знаний, умений и навыков выпускников;

5. Разрабатывать и внедрять «интеллектуальные» электронные тренинговые системы и виртуальные лаборатории для обеспечения выработки у студентов необходимых навыков и умений. Если знания можно приобрести при самостоятельном изучении учебных материалов, то выработать навыки и умения самостоятельно, как правило, не представляется возможным;

6. Интеллектуальные электронные тренинговые системы должны проектироваться отдельными модулями, ориентированными на задачи практического характера.

Таким образом, оптимизации электронного обучение с учетом выше описанных проблем, позволит приблизить данный метод обучения к традиционному, и выразить его как современный способ получения полноценного образования с преимуществом получения опыта и знаний в современных технологиях.

Электронное обучение и информационно-коммуникационные технологии не призваны заменить собой традиционные формы обучения, или вытеснить педагогов из образования. Их роль заключается в изменении ролей преподавателя и студента в учебном процессе, характера их взаимодействия между собой. При использовании электронного обучения преподаватель выступает не в роли передатчика готовых знаний, а занимается консультациями студентов, помогая им находить собственные пути обучения, обучая самостоятельной работе по изучению материала. А студенты, вместо пассивного прослушивания лекций, начинают активно участвовать в процессе создания и накопления новых знаний. Объектная экономика сможет определить новые профессии на рынке образовательных услуг: к примеру, объектного архитектора, в задачу которого бу- 
дет входить проектирование образовательных компонентов, строителя объектов, который будет работать с мультимедийными средствами для создания объектов обучения, соответствующих стандартам; сборщика объектов, собирающего вместе «родственные» объекты для формирования полноценного учебного курса; предметного эксперта; имитатора, который окружает обучающегося визуальными объектами, звуками и ощущениями реальной среды.

Достижения в области виртуальной реальности могут иметь широкое применение в различных практико-ориентированных областях, например при обучении действиям в чрезвычайных ситуациях медиков - хирургов, медсестер и др., пилотов, милицейских служащих и т.д. Имитации также ценны при обучении общению, управлению, другим межличностным навыкам. Таким образом, можно согласиться с автором Е.М. Бурнаева, что классическое образование невозможно заменить электронным; ассортимент продуктов, предлагаемых на рынке e-learning, не может конкурировать с традиционными программами. Но они способствуют развитию интересных гибридных проектов на базе комбинаций образовательных информационных технологий. Бесспорно, что интерактивные тренажеры, виртуальные экскурсии, электронные «репетиторы», консультационные услуги позволяют преподавателю более эффективно использовать учебное время.

\section{Список используемых источников:}

1. Федеральный закон от 29.12.2012 N 273-ФЗ «Об образовании в Российской Федерации» ред. от 14.12.2015. URL: http://www.consultant.ru/document/_cons_doc_LAW_149753/

2. Бурнаева Е.М. «Человек виртуальный» как проблема электронного образования // Ученые заметки ТОГУ. Т. 4. 2013. № 4. С. 1243-1246.

3. Калмыкова О.В., Черепанов А.А. Реализация принципов дистанционного обучения при преподавании информатики // Экономика, статистика и информатика. Вестник УМО. М. 2014. № 3. С. 17-22.

4. Карпенко О.М., Абрамова А.В., Широкова М.Е., Басов В.А. Обзор средств организации электронного обучения и перспективы их развития // Дистанционное и виртуальное обучение. 2015. № 2 (92).

C. 4-24.

5. Лебедев С.А., Лебедев В.А. Перспективы развития электронного обучения и дистанционных образовательных технологий // Совершенствование подготовки ИТ-специалистов по направлению "Прикладная информатика" для инновационной экономики. 2014. С. 75-78.

6. Логинова А.В. Эволюция электронного обучения и перспективы развития // Молодой ученый. 2015. № 10 (90). С. 1210-1212.

7. Петруня О.Э. Методология электронного обучения: проблемы и перспективы // Преподаватель в среде e-learning Сборник докладов и тезисов Форума. Московский государственный университет экономики, статистики и информатики. 2014. С. 117-121.

8. Сергеев С.Ф. Дидактика электронного обучения: проблемы и перспективы развития // НародноАе образование. 2015. № 4. С. 109-117.

(C) 2015, Ермашенок Е.В.

Проблемы и перспективы использования электронного обучения в образовательном процессе
(C) 2015, Ermashenok E.V.

Problems and prospects of use of electronic training in educational process 